\title{
ANALISIS FAKTOR PENDORONG REALISASI MANFAAT IMPLEMENTASI ERP DI PERUSAHAAN INDONESIA
}

\author{
Iqbal Yulizar $\mathbf{M}^{*}$, Rajesri Govindaraju ${ }^{* *}$ \\ ${ }^{*}$ Fakultas Teknik, Program Studi Teknik Industri, Universitas Widyatama \\ ERP Center, Universitas Widyatama. Jl. Cikutra No.204A, Bandung \\ ${ }^{* *}$ Fakultas Teknologi Industri, Program Studi Teknik Industri, Institut Teknologi Bandung
}

(Received: Octobre 17, 2016 / Accepted: February 28, 2017)

\begin{abstract}
Abstrak
Pengelolaan implementasi ERP pada fase post project yaitu fase ketika ERP telah digunakan secara integral dalam perusahaan, menentukan terealisasinya manfaat dari implementasi ERP, karenanya terkait pengelolaan pada fase post project ini dibutuhkan kajian lebih lanjut untuk mengetahui upaya-upaya merealisasikan manfaat dari implementasi ERP. Penelitian ini bertujuan untuk mengetahui bagaimana mengukur manfaat implementasi ERP dan mengetahui sejauh mana perusahaan-perusahaan Indonesia merealisasikan manfaat implementasi ERP, serta memberikan rekomendasi bagi perusahaan-perusahaan di Indonesia dalam menjalani fase post project agar manfaat dari implementasi ERP dapat direalisasikan. Model pengelolaan pada fase post project yang dikembangkan dalam penelitian ini didasarkan pada penelitian-penelitian sebelumnya yang mengkaji kelompok aktivitas pada fase post project, dimana institutionalized ERP system dan improved ERP system dapat mendorong perusahaan untuk merealisasikan manfaat implementasi ERP.
\end{abstract}

Kata Kunci : implementasi ERP; realiasi manfaat; institutionalized ERP system; improved ERP system; partial leat square; fase post project.

\begin{abstract}
Management of ERP implementation phase is the phase when the project post ERP has been used integrally within the company, determine the realization of the benefits of an ERP implementation, hence related to the management phase of this project post further study is needed to determine the efforts to realize the benefits of ERP implementation. This study aims to determine how to measure the benefits of ERP implementation and determine the extent of Indonesian companies realize the benefits of ERP implementation, as well as provide recommendations to firms in Indonesia in carrying out post-project phase in order to benefit from the ERP implementation can be realized. Model management in the postphase project being developed in this study was based on previous studies that assess the activity group on post-phase project, which institutionalized the ERP system and improved ERP system can encourage firms to realize the benefits of ERP implementation.
\end{abstract}

Keywords : ERP implementation; realization of the benefits; institutinalized ERP system; improved ERP system; partial leat square; face post project.

\section{Pendahuluan}

Sejak tahun 1990-an, Enterprise Resource Planning (ERP) telah menjadi sistem teknologi informasi yang diadopsi oleh banyak perusahaan untuk meningkatkan keunggulan kompetitif perusahaan melalui efisiensi proses bisnis (Gupta,\& Kohli, 2006). ERP merupakan paket sistem informasi

\footnotetext{
*) Penulis Korespondensi.

email: iqbal.yulizar@widyatama.ac.id;

rajesri_g@yahoo.com
}

yang mengintegrasikan informasi dalam suatu area fungsional atau antar area fungsional dalam perusahaan (Govindaraju, 2002).

Untuk mengimplementasikan ERP, perusahaan menginvestasikan dana dan waktu yang tidak sedikit. Berdasarkan hasil survey Meta Group terhadap 63 perusahaan yang mempunyai pendapatan antara 12 juta dolar sampai 43 miliar dolar, diperoleh data bahwa rata-rata dana yang dikeluarkan oleh perusahaan-perusahaan untuk mengimplementasikan ERP adalah sebesar 10,6 juta dolar dan waktu yang dibutuhkan untuk mengimplementasikan adalah 
selama 23 bulan (Umble et al., 2003). Meskipun dana dan waktu telah banyak diinvestasikan, tidak semua perusahaan berhasil merealisasikan manfaat dari implementasi ERP yang dilakukannya. Kegagalan merealisasikan manfaat implementasi ERP ini ditunjukkan dengan tingginya inventori, penurunan pendapatan, dan kehilangan return on investment (Martua, 2006).

Untuk kondisi implementasi ERP di Indonesia, hasil studi kasus pada beberapa perusahaan besar di Indonesia menunjukkan bahwa pencapaian manfaat dari implementasi ERP belum begitu maksimal. Pada PT. Mitsubishi Chemical Indonesia, pemahaman pengguna mengenai sistem ERP masih rendah dan pengguna merasa kesulitan dalam menggunakan ERP sehingga kinerja perusahaan menurun (Martua, 2006). Pada PT. Indosat Tbk, hasil studi kasus terkait dengan evaluasi kesuksesan implementasi ERP menunjukkan bahwa ERP belum dapat meningkatkan tingkat produktivitas, belum dapat mengurangi biaya organisasi, dan belum dapat meningkatkan kepuasan pelanggan (Novriani, 2008). Pada PT. Danone Dairy Indonesia, akurasi dan kecepatan untuk mendapatkan informasi masih belum begitu baik, hal ini ditandai dengan seringnya keluhan pengguna akibat adanya redudansi data dalam ERP (Handayani, 2009).

Kegagalan realisasi manfaat dari implementasi ERP ini disebabkan karena kurang baiknya pengelolaan ERP pada fase post project, yaitu fase dimana ERP telah digunakan (Botta \& Millet, 2005; Deloitte, 1999; Govindaraju et.al., 2001). Namun demikian, paling tidak hingga tahun 2005 penelitianpenelitian terkait implementasi ERP sebagian besar terfokus pada tahap project implementasi ERP, fase post project masih mendapat sedikit perhatian, padahal tahap ini adalah tahap dimana return on invesment yang sesungguhnya didapatkan (Botta \& Millet, 2005). Penelitian terdahulu lebih banyak berfokus pada aspek teknis dari implementasi ERP dan tidak terlalu komprehensif dalam mengkaji pengelolaan ERP di fase post project, oleh karena itu, walaupun sudah pernah dilakukan penelitianpenelitian yang berkaitan dengan fase post project masih dibutuhkan penelitian yang membahas pengelolaan ERP secara lebih komprehensif di fase post project (Ehie \& Madsen, 2005; Berchet \& Habchi, 2005; Shank et.al., 2000; Ross \& Vitale, 2000; Rajagopal, 2002; Ahituv et.al., 2002). Penelitianpenelitian sebelumnya belum mengkaji pengelolaan ERP pada fase post-project dan keterkaitannya dengan realisasi manfaat dari implementasi ERP, sehingga untuk dapat merealisasikan manfaat dari implementasi ERP, terutama pada perusahaan-perusahaan di Indonesia, perlu dilakukan penelitian yang mengkaji pengelolaan ERP pada fase post project untuk perusahaan-perusahaan di Indonesia.

\section{Kajian Literatur}

Untuk dapat mengetahui bagaimana mengukur realisasi manfaat dari implementasi ERP dan faktor- faktor yang mendorong realisasi manfaat dari implementasi ERP, dilakukan studi terhadap literaturliteratur terkait.

A. Sistem Enterprise Resource Planning (ERP)

Enterprise Resource Planning (ERP) merupakan paket sistem informasi yang mengintegrasikan informasi dalam suatu area fungsional dan antar area fungsional dalam perusahaan (Kumar \& Hillegersberg, 2000 dalam Govindaraju 2002).

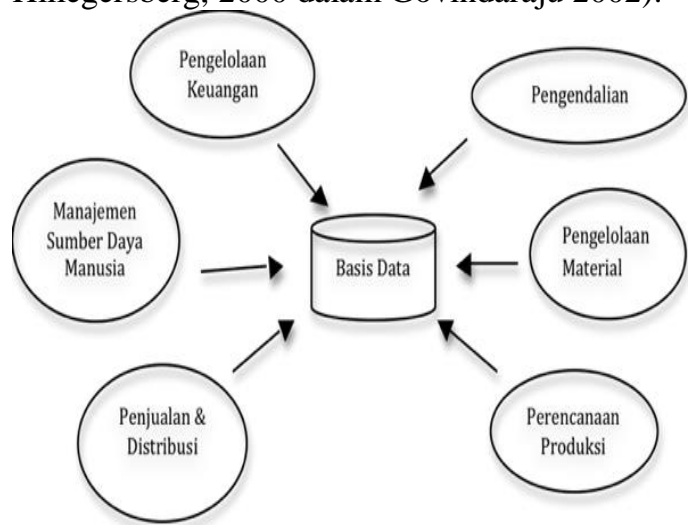

Gambar 1. Illustrasi Sistem ERP

ERP adalah tulang punggung dari sistem informasi suatu enterprise. Inti dari software ini adalah basis data terpusat yang mendapatkan dan memberikan data kepada berbagai aplikasi modular yang dioperasikan dalam sistem komputer yang sama. Pada Gambar 1, diilustrasikan modul-modul dalam ERP mencakup berbagai fungsi-fungsi dalam bisnis, seperti manufaktur, manajemen rantai suplai, keuangan, proyek, sumber daya manusia, dan manajemen hubungan pelanggan.

Modul-modul dalam paket ERP ini dapat disesuaikan dengan kebutuhan spesifik organisasi. Menggunakan ERP, data yang redundan dapat dihindari karena data hanya perlu dimasukkan satu kali ke dalam basis data. Sistem ini menyediakan konsistensi dan transparansi pada keseluruhan enterprise sehingga memberikan akses informasi yang terpercaya dan terintegrasi (Botta-Genoulaz \& Millet, 2005; Esteves \& Pastor, 2001).

B. Kajian Perspektif dalam Implementasi ERP

Implementasi ERP dapat dilihat dari 3 perspektif, yaitu:

1. Perspektif organisasi

Implementasi ERP dapat dilihat dari perspektif organisasi, karena implementasi ERP berkonsikuensi pada dibutuhkannya kompetensi baru dan penyesuaian dari setiap orang dalam organisasi. Hal ini dikarenakan adanya perubahan sistem yang digunakan sebelum dan sesudah implementasi ERP dilakukan (Kræmmergaard \& Møller, 2000).

2. Perspektif bisnis

Implementasi ERP dapat dilihat dari perspektif bisnis, karena implementasi ERP berkonsikuensi pada berubahnya proses bisnis 
dalam organisasi, bahkan membawa organisasi menuju bisnis yang benar-benar baru (Kræmmergaard \& Møller, 2000).

3. Perspektif teknologi

Implementasi ERP dapat dilihat dari perspektif teknologi, karena ERP adalah suatu sistem software yang cukup kompleks, yang dimana dalam implementasinya tentu memiliki tantangan yang cukup besar dari sisi teknis (Kræmmergaard \& Møller, 2000).

C. Kajian Pengelolaan ERP pada Fase Post Project Kajian mengenai pengelolaan ERP pada fase post project, terkait dengan kelompok-kelompok aktivitas yang ada pada pada fase post project. Berdasarkan studi literatur terhadap penelitianpenelitian yang terkait dengan kelompok aktivitas pada fase post project, dapat disimpulkan bahwa terdapat dua kelompok aktivitas utama pada fase post project, yaitu institutionalization dan continuous improvement (Delloite, 1999; Esteves \& Pastor, 2005; Markus \& Tanis, 1999; Ross \& Vitale, 2000; Shanks, et.al., 2000; Govindaraju, 2001). Institutionalization adalah suatu proses untuk mencapai keadaan dimana penggunaan ERP telah menjadi sesuatu yang normal dan rutin dalam operasional perusahaan dan pengguna merasa nyaman dalam menggunakan ERP tersebut (Avgerou, 2000; Esteves \& Pastor, 2001).Continuous improvement adalah peningkatan kapabilitas ERP yang ada secara berkelanjutan sehingga terjadi peningkatan performansi dan efisiensi proses bisnis perusahaan. Kedua aktivitas ini merupakan kelompok aktivitas penting yang menentukan tercapainya manfaat yang diharapkan dari implementasi ERP yang dilakukan oleh perusahaan (Govindaraju, et.al., 2001).

\section{Pengembangan Model Dan Hipotesis Penelitian}

Perusahaan-perusahaan telah menginvestasikan dana dan waktu yang tidak sedikit untuk mengimplementasikan ERP. Implementasi ERP ini dilakukan agar perusahaan-perusahaan mendapatkan manfaat dari implementasi ERP. Sejalan dengan 3 perspektif dalam implementasi ERP yaitu perspektif bisnis, perspektif teknologi, dan perspektif organisasi (Kræmmergaard \& Møller, 2000), manfaat dari implementasi ERP dapat dibagi menjadi tiga kelompok, yaitu manfaat bisnis, manfaat teknologi, dan manfaat organisasi. Manfaat bisnis adalah manfaat dari implementasi ERP yang berkaitan dengan pengelolaan manajerial, proses bisnis dan perencanaan strategis perusahaan. Manfaat teknologi adalah manfaat dari implementasi ERP yang berkaitan dengan infrastruktur teknologi dalam perusahaan. Manfaat organisasi adalah manfaat dari implementasi ERP yang berkaitan dengan sumber daya manusia dan budaya kerja dalam perusahaan. Realisasi dari ketiga kelompok manfaat implementasi ERP menjadi perhatian utama dalam penelitian ini karena meskipun perusahaan-perusahaan telah menginvestasikan dana dan waktu yang tidak sedikit tidak semua perusahaan berhasil merealisasikan manfaat dari implementasi ERP, sehingga variabel dependen dalam penelitian ini adalah variabel realisasi manfaat bisnis, realisasi manfaat teknologi, dan realisasi manfaat organisasi.

Berdasarkan kajian-kajian yang membahas kelompok-kelompok aktivitas pada fase post project, institutionalization dan continuous improvement menentukan tercapainya manfaat yang diharapkan dari implementasi ERP yang dilakukan oleh perusahaan (Govindaraju, et.al., 2001). Dilakukannya aktivitas-aktivitas institutionalization akan membuat tercapainya instititutionalized ERP system yaitu suatu kondisi dimana penggunaan ERP telah menjadi sesuatu yang normal dan rutin dalam operasional perusahaan dan pengguna merasa nyaman dalam menggunakan ERP tersebut. Dilakukannya aktivitasaktivitas continuous improvement pada ERP akan membuat tercapainya improved ERP system yaitu suatu kondisi dimana kapabilitas ERP yang ada meningkat sehingga terjadi peningkatan performansi dan efisiensi proses bisnis perusahaan.

\section{A. Institutionalized ERP system}

Institutionalized ERP system merupakan suatu kondisi dimana penggunaan ERP telah menjadi sesuatu yang normal dan rutin dalam operasional perusahaan dan pengguna merasa nyaman dalam menggunakan ERP tersebut. Kondisi ini dapat dicapai melalui aktivitas-aktivitas institusionaliasi yang dilakukan dalam perusahaan. Ketika ERP di perusahaan telah terinstitusionalisasi dengan baik, penggunaan ERP akan berdampak pada terpenuhinya kebutuhan-kebutuhan bisnis perusahaan (Markus \& Tanis, 1999), pengguna merasa puas dalam menggunakan sistem yang ada (Govindaraju, et., al., 2001), serta mendorong perubahan budaya dan struktur organisasi ke arah yang lebih baik dan efisien (Kumar et.al., 2002; Motwani et.al., 2002). Dengan demikian, institutionalized ERP system akan berdampak positif pada realisasi manfaat bisnis dan manfaat organisasi dalam perusahaan.

Hipotesis $1\left(\mathrm{H}_{1}\right)$ : Institutionalized ERP system berpengaruh positif terhadap realisasi manfaat bisnis dari implementasi ERP.

Hipotesis $2\left(\mathrm{H}_{2}\right)$ : Institutionalized ERP system berpengaruh positif terhadap realisasi manfaat organisasi dari implementasi ERP.

B. Improved ERP system

Improved ERP system merupakan suatu kondisi dimana kapabilitas ERP yang ada meningkat sehingga terjadi peningkatan performansi dan efisiensi proses bisnis perusahaan. Kondisi ini dapat dicapai melalui aktivitas-aktivitas perbaikan yang berkelanjutan terkait ERP yang dilakukan dalam perusahaan. Peningkatan kapabilitas dari ERP yang dilakukan akan mendukung efisiensi proses bisnis, perencanaan dan pelaksanaan tujuan bisnis strategis perusahaan (Esteves \& Pastor, 1999; Berchet \& 
Habchi, 2005; Chou \& Yang, 2008), serta berdampak positif terhadap kestabilan dan fleksibilitas infrastruktur teknologi informasi di perusahaan (Kumar et.al., 2002; Berchet \& Habchi, 2005; Botta-Genoulaz \& Millet, 2005). Dengan demikian, improved ERP system akan berdampak positif pada realisasi manfaat bisnis dan manfaat teknologi dalam perusahaan.

Hipotesis $3 \quad\left(\mathrm{H}_{3}\right)$ : Improved ERP system berpengaruh positif terhadap realisasi manfaat bisnis dari implementasi ERP.

Hipotesis $4 \quad\left(\mathrm{H}_{4}\right)$ : Improved ERP system berpengaruh positif terhadap realisasi manfaat teknologi dari implementasi ERP.

Pada Gambar 1. merupakan model penelitian yang digunakan.

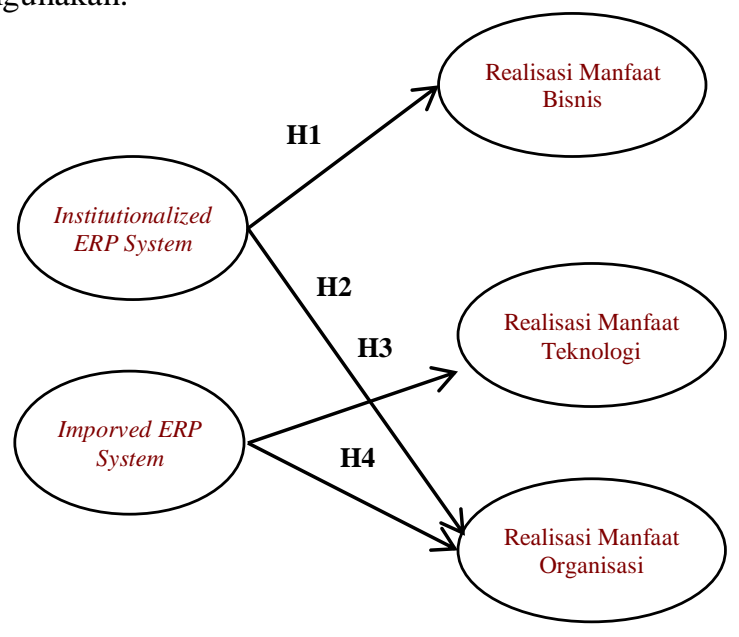

Gambar 1. Model Penelitian

\section{Pengumpulan Data}

Metode pengumpulan data yang digunakan pada penelitian ini adalah metode survey dengan kuesioner yang disebar ke perusahaan-perusahaan yang menjadi objek penelitian. Proses pengumpulan data diawali dengan mengidentifikasi sampel penelitian hingga kemudian kuisioner disebarkan pada responden.

\section{A. Indentifikasi Sampel Penelitian}

Populasi dalam penelitian ini adalah perusahaanperusahaan di Indonesia yang telah mengimplementasikan ERP di perusahaannya dan telah memasuki fase dimana ERP tersebut telah digunakan dalam operasional perusahaan paling sedikit selama 1 tahun. Pemilihan responden sebagai sampel dalam survey ini menggunakan metode judgment sampling dimana responden yang dipilih berada dalam posisi terbaik yang dapat memberikan informasi yang diperlukan (Sekaran, 2006). Metode ini digunakan karena untuk mendapatkan informasi terkait pencapaian manfaat dari implementasi ERP, responden yang dipilih haruslah seorang wakil dari perusahaan yang mengetahui pengelolaan implementasi ERP di perusahaannya.

\section{B. Penyusunan Kuisioner}

Penentuan jumlah dan isi butir pernyataan dalam kuisioner dilakukan dengan mengacu pada indikator-indikator dari tiap-tiap variabel penelitian. Metode penskalaan yang digunakan adalah metode penskalaan numerikal memiliki 10 titik pilihan (terdiri dari poin $1 \mathrm{~s} / \mathrm{d}$ 10) dengan dua kutub, dimana poin 1 menyatakan sangat tidak baik/sangat tidak benar/sangat tidak setuju/sangat jarang dan poin 10 menyatakan sangat baik/sangat benar/sangat setuju/sangat sering. Responden diminta untuk memilih salah satu dari poin yang tersedia. Penggunakan skala numerikal ini secara konsisten memberikan persentase pernyataan terjawab lebih tinggi daripada pernyataan terbuka (Brace, 2008). Secara umum, pilihan penilaian yang terdiri dari poin $1 \mathrm{~s} / \mathrm{d} 10$ cukup popular digunakan dalam menilai persepsi seseorang dan memberikan validitas dan kekuatan ekplanatori yang lebih besar daripada penskalaan 5 titik pilihan (Coelho \& Esteves, 2010). Poin jawaban yang berjumlah genap dipilih agar responden tidak cenderung memilih poin tengah dari poin jawaban yang tersedia (Coelho \& Esteves, 2010).

C. Penyebaran Kuisioner

Kuisioner yang disebar dalam penelitian berjumlah 78 buah kuisioner dan menghasilkan 44 buah atau 56,41\% hasil kusioner yang dikembalikan. Dari 44 buah kusioner yang dikembalikan, 3 buah kuisioner atau 6,8\% dari hasil kuisioner yang dikembalikan dinyatakan tidak valid dikarenakan perusahaan bersangkutan belum menggunakan ERP sepenuhnya, sehingga kusioner yang dapat diolah berjumlah 41 buah kuisioner atau 52,56\% dari total kuisioner yang disebar. Penyebaran kuisioner dilakukan dengan beberapa cara yaitu kuisioner diberikan secara pribadi, melalui surat, dan email. Penyebaran dilakukan pada bulan Maret - April 2010.

\section{Pengolahan Dan Analisis Data}

Berdasarkan data hasil survey yang terkumpul, dilakukan pengolahan data yang dilakukan mencakup evaluasi item pernyataan, statistik deskriptif, dan evaluasi model struktural. Evaluasi model struktural pada penelitian ini menggunakan metode partial least square (PLS), yang merupakan metode structural equation modelling berbasis variansi. Metode ini dapat diandalkan dikarenakan tidak mengasumsikan data harus menggunakan skala pengukuran tertentu, dan membutuhkan jumlah sampel yang kecil.

\section{A. Demografi Perusahaan}

Mayoritas dari perusahaan tercakup dalam survey penelitian ini, berdasarkan kriteria dari Badan Pusat Statistik RI tahun 2009 dapat digolongkan sebagai perusahaan besar, dikarenakan semua perusahaan yang disurvey memiliki jumlah karyawan lebih dari 99 orang. Dari sisi tingkat penghasilan, $73.17 \%$ dari perusahaan-perusahaan yang disurvey memiliki tingkat penghasilan 
pertahunnya sebesar lebih dari Rp. 50 milyar, hanya $26.83 \%$ diantaranya yang berpenghasilan antara Rp. 2.5 milyar - Rp. 50 milyar.

Jenis industri dari perusahaan-perusahaan yang disurvey dikelompokan kedalam 4 kategori, yaitu jasa (42\%), manufaktur (24\%), hasil bumi (17\%), dan telekomunikasi (17\%). Pada Gambar 1. merupakan jenis industri perusahaan pada responden.

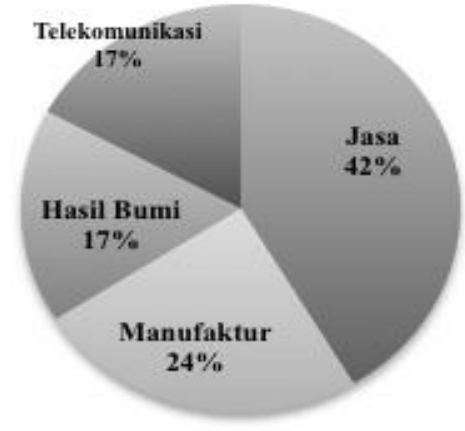

Gambar 2. Jenis Industri Perusahaan Responden

Vendor ERP dari perusahaan yang disurvey dikelompokan kedalam 5 vendor, yaitu SAP (49\%), Oracle $(22 \%)$, JD Edwards (5\%), Ms. Dynamics (5\%), dan Lainnya (19\%).

Lama ERP telah digunakan dalam operasional oleh perusahaan yang disurvey dikelompokan kedalam 5 kelompok yaitu 1 tahun (15\%), 2 tahun (7\%), 3 tahun $(2 \%)$, dan $>3$ tahun $(76 \%)$. Pada Gambar 3. merupakan vendor ERP perusahaan responden. Dan Gambar 4. merupakan lama penggunaan ERP oleh perusahaan responden.

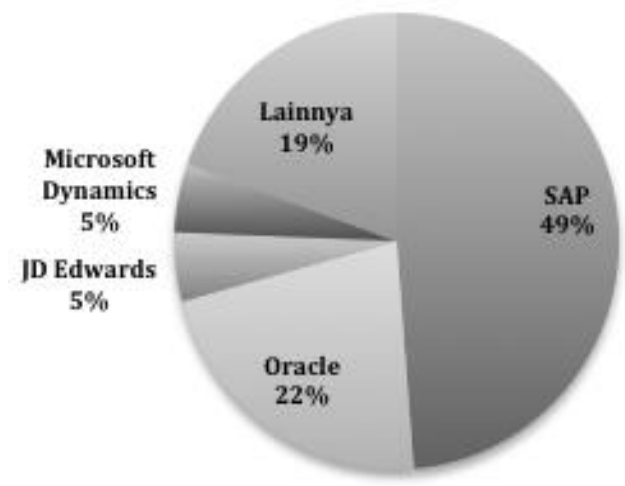

Gambar 3. Vendor ERP Perusahaan Responded

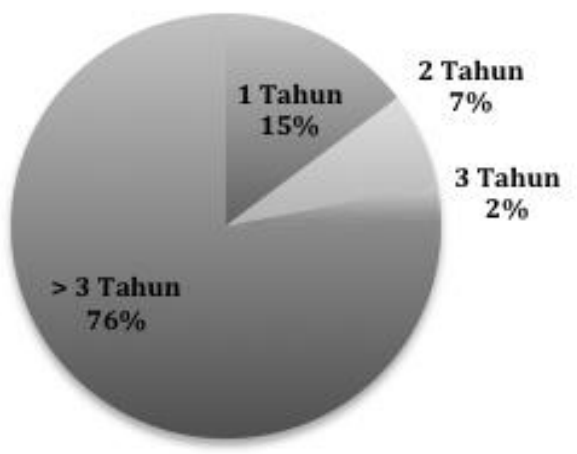

Gambar 4. Lama Penggunaan ERP oleh Perusahaan Responden

B. Pencapaian Manfaat ERP

Berdasarkan hasil survey, secara umum rata-rata perusahaan telah mulai mendapatkan manfaat dari implementasi ERP yang dilakukan (Gambar 5).

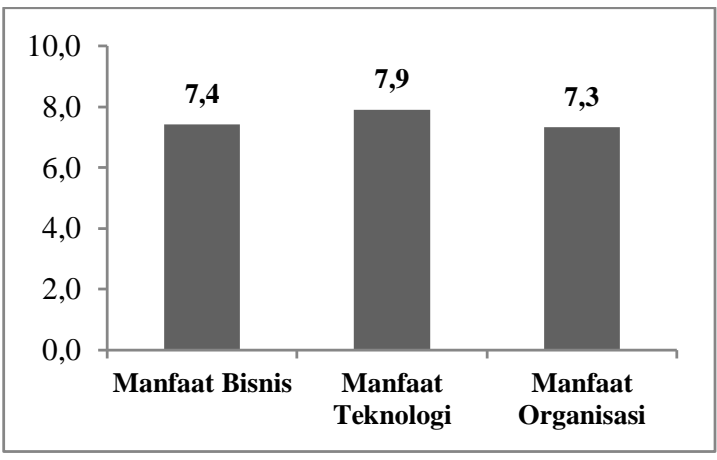

Gambar 5. Ketercapaian Manfaat Implementasi ERP

Pada perspektif bisnis, rata-rata nilai perusahaan responden adalah 7,4. Hal ini menunjukkan bahwa dengan adanya ERP, proses bisnis perusahaan mulai menjadi lebih efisien dan efektif. Dilihat perspektif teknologi, rata-rata nilai perusahaan responden adalah 7,9. Hal ini menunjukkan bahwa dengan implementasi ERP, infrastruktur teknologi informasi yang ada menjadi lebih stabil dan efisien. Untuk perspektif organisasi, rata-rata nilai perusahaan responden adalah 7,3. Hal ini menunjukkan bahwa dengan adanya ERP, komunikasi internal dan antar departemen lebih efektif, terjadi peningkatan kemampuan karyawan dalam bidang kerjanya, dan perilaku karyawan telah mendukung kelancaran alian kerja secara keseluruhan dalam perusahaan. 


\section{Evaluasi Model Struktural}

Evaluasi model struktural dilakukan untuk menguji hipotesis-hipotesis dalam penelitian ini. Evaluasi dilakukan menggunakan analisis jalur (path analysis) dengan mengukur koefisien jalur (path coefficient) antar variabel-variabel dalam hipotesis dan melihat nilai $\mathrm{R}^{2}$ variabel laten endogen (Tabel 1).

Tabel 1. Nilai koefisien jalur dan $\mathrm{r}^{2}$

\begin{tabular}{cllll}
\hline & $\begin{array}{l}\text { Origin } \\
\text { al } \\
\text { Sample } \\
(\mathbf{O})\end{array}$ & $\begin{array}{l}\text { T- } \\
\text { Statistics } \\
(\mid \mathbf{O} / \text { STER } \\
\mathbf{R})\end{array}$ & & \\
& 0.5234 & 3.316046 & INS & 0.6789 \\
IMP -> & 0.6103 & 8.804738 & KS & \\
IMP -> & 0.6103 & $\mathbf{R}^{2}$ \\
INS -> & 0.3413 & 2.389487 & MB & 0.6825 \\
INS -> & 0.0155 & 13.97582 & MO & $\begin{array}{c}0.6651 \\
77\end{array}$ \\
MO & 84 & & & \\
\hline
\end{tabular}

Hipotesis 1 (H): Institutionalized ERP system berpengaruh positif terhadap realisasi manfaat bisnis dari implementasi ERP; t-statistik $=2,38>\mathrm{t}$ tabel $=1,96$; Koefisien parameter $=0,34$; Hipotesis diterima.

Hal ini sejalan dengan teori yang membangun hipotesis ini dimana ketika ERP di perusahaan telah terinstitusionalisasi dengan baik, penggunaan ERP akan berdampak pada terpenuhinya kebutuhankebutuhan bisnis perusahaan (Markus \& Tanis, 1999).

Hipotesis $3 \quad\left(\mathbf{H}_{3}\right)$ : Improved ERP system berpengaruh positif terhadap realisasi manfaat bisnis dari implementasi ERP; t-statistik = 3,316 > t-tabel $=1,96 ;$ Koefisien parameter $=0,523$; Hipotesis diterima.

Hal ini sejalan dengan teori yang membangun hipotesis ini dimana peningkatan kapabilitas dari ERP akan mendukung efisiensi proses bisnis, perencanaan dan pelaksanaan tujuan bisnis strategis perusahaan (Esteves \& Pastor, 1999; Berchet \& Habchi, 2005; Chou \& Chang, 2008).

Berdasarkan evaluasi $\mathrm{H}_{1}$, dan $\mathrm{H}_{3}$ diatas, dapat disimpulkan bahwa berdasarkan hasil survey, realisasi manfaat bisnis dari implementasi ERP dipengaruhi secara positif oleh institutionalized ERP system dan improved ERP system.

Evaluasi nilai $\mathrm{R}^{2}$ menunjukkan bahwa variabilitas dari variabel laten Realisasi Manfaat Bisnis (MB) dijelaskan sebanyak $68,25 \%$ oleh variabel-variabel yang mempengaruhinya. Ini menunjukkan bahwa model hubungan variabel-variabel laten yang mempengaruhi variabel laten Realisasi Manfaat Bisnis (MB) dapat dikatakan cukup baik.

Hipotesis $4 \quad\left(\mathbf{H}_{4}\right)$ : Improved ERP system berpengaruh positif terhadap realisasi manfaat teknologi dari implementasi ERP; t-statistik =
$8.804>$ t-tabel $=1,96 ;$ Koefisien parameter $=0,610$; Hipotesis diterima.

Hal ini sejalan dengan teori yang membangun hipotesis ini dimana peningkatan kapabilitas dari ERP yang dilakukan akan mendukung tingkat kestabilan dan fleksibilitas infrastruktur teknologi informasi di perusahaan (Kumar et al., 2002, Berchet \& Habchi, 2005; Botta-Genoulaz \& Millet, 2005).

Evaluasi nilai $\mathrm{R}^{2}$ menunjukkan bahwa variabilitas dari variabel laten Realisasi Manfaat Teknologi (MT) hanya dijelaskan sebanyak 37,2\% oleh variabel-variabel yang mempengaruhinya. Artinya masih perlu dilakukan penelitian lanjutan untuk lebih mengeksplorasi variabel-variabel lain yang mempengaruhi realisasi manfaat teknologi dari implementasi ERP.

Hipotesis 2 ( $\left.\mathbf{H}_{2}\right)$ : Institutionalized ERP system berpengaruh positif terhadap realisasi manfaat organisasi dari implementasi ERP; t-statistik = $8,140>$ t-tabel $=1,96$; Koefisien parameter $=0,688$; Hipotesis diterima.

Hal ini sejalan dengan teori yang membangun hipotesis ini dimana kondisi ERP yang telah terinstitusionalisasi di dalam perusahaan akan membuat karyawan merasa puas menggunakan sistem informasi yang baru, dan mendorong perubahan budaya dan struktur organisasi perusahaan ke arah yang lebih baik dan efisien (Kumar et al., 2002; Shang \& Seddon, 2000; Govindaraju, 2001).

Evaluasi nilai $\mathrm{R}^{2}$ menunjukkan bahwa variabilitas dari variabel laten Realisasi Manfaat Organisasi (MO) dijelaskan sebanyak $66,51 \%$ oleh variabelvariabel yang mempengaruhinya. Ini menunjukkan bahwa model hubungan variabel-variabel laten yang mempengaruhi variabel laten Realisasi Manfaat Organisasi (MO) dapat dikatakan cukup baik.

\section{Kesimpulan}

Berdasarkan hasil survey yang dilakukan dalam penelitian ini, dapat disimpulkan beberapa temuan sebagai berikut:

Realisasi manfaat implementasi ERP dapat dibagi menjadi tiga kelompok, yaitu realisasi manfaat bisnis, realisasi manfaat teknologi, dan realisasi manfaat organisasi. Hal ini didasarkan pada 3 sudut pandang dalam implementasi ERP yaitu sudut pandang bisnis, sudut pandang teknologi, dan sudut pandang organisasi.

Berdasarkan hasil pengolahan, nilai rata-rata realisasi manfaat yang paling dirasakan dari implementasi ERP adalah realisasi manfaat dari sisi teknologi, dan jika dilihat secara umum perusahaanperusahaan yang disurvey telah merasakan manfaat dari implementasi ERP namun pencapaiannya belum maksimal. 
Secara umum rata-rata perusahaan telah mulai mendapatkan manfaat dari implementasi ERP yang dilakukan. Pada skala 1 sampai dengan 10, nilai ratarata manfaat ERP yang dirasakan oleh perusahaan pada perspektif bisnis, teknologi, dan organisasi secara berututan adalah 7,4, 7,9, dan 7,3. Hasil ini menunjukkan bahwa:

a. Pada perspektif bisnis, ERP yang ada telah mendorong proses bisnis perusahaan mulai menjadi lebih efisien dan efektif.

b. Pada perspektif teknologi, implementasi ERP mendorong infrastruktur teknologi informasi yang ada menjadi lebih stabil dan efisien.

c. Pada perspektif organisasi, ERP telah mendorong perubahan cara kerja pegawai menjadi lebih tertata dan efektif.

Terdapat dua faktor yang dapat mendorong terjadinya realisasi manfaat dari implementasi ERP, yaitu institutionalized ERP system dan improved ERP system.

Faktor institutionalized ERP system berpengaruh positif terhadap realisasi manfaat bisnis dari implementasi ERP. Hal ini sejalan dengan teori yang membangun hipotesis ini dimana ketika ERP di perusahaan telah terinstitusionalisasi dengan baik, penggunaan ERP akan berdampak pada terpenuhinya kebutuhan-kebutuhan bisnis perusahaan (Markus \& Tanis, 1999).

Improved ERP system berpengaruh positif terhadap realisasi manfaat bisnis dari implementasi ERP. Hal ini sejalan dengan teori yang membangun hipotesis ini dimana peningkatan kapabilitas dari ERP akan mendukung efisiensi proses bisnis, perencanaan dan pelaksanaan tujuan bisnis strategis perusahaan (Esteves \& Pastor, 1999; Berchet \& Habchi, 2005; Chou \& Chang, 2008).

\section{Daftar Pustaka}

Ahituv, N., Neumann, S., \& Zviran, M. (2002). A System Development Methodology for ERP Systems. The Journal of Computer Information Systems , 42 (3).

Al-Mudimigh, A., Zairi, M., \& Al-Mashari, M. (2001). ERP software implementation: an integrative framework. European Journal of Information Systems , 10, 216-226.

Avgerou, C. (2000). IT and organizational change : an institutionalist perspective. Information technology and people , 13 (4), 234-262.

Badan Pusat Statistik. (n.d.). Retrieved June 6, 2010, from

http://www.bps.go.id/aboutus.php?glos=1\&ist $=1 \&$ var $=\mathrm{I} \& \mathrm{car} \mathrm{i}=\& \mathrm{kl}=1$

Berchet, C., \& Habchi, G. (2005). The implementation and deployment of an ERP system: An industrial case study. Computers in Industry , 56.

Botta-Genoulaz, V., \& Millet, P. A. (2005). A Classification for better use of ERP Systems. Computers in Industry, 56.
Boudreau, M.-C. (2002). Learning to Use ERP Technology: a Causal Model. The 36th Hawaii International Conference on System Sciences (HICSS). IEEE.

Brace, I. (2008). Questionnaire Design: How to Plan, Structure and Write Survey Material for Effective Market Research (Market Research in Practice) (2nd Edition ed.). Philadelphia, USA: Kogan Page Limited.

Chou, S.-W., \& Chang, Y.-C. (2008). The implementation factors that influence the ERP (enterprise resource planning) benefits. Decision Support Systems , 46, 149-157.

Coelho, P., \& Esteves, S. (n.d.). The choice between a 5-point and a 10-point scale in the framework of customer satisfaction measurement. Retrieved June 5, 2010, from http://www.isegi.unl.pt/investigacao/cegi/NE/ download\%5CScales\%20IJMR\%20final.pdf

Delloite Consulting. (1999). ERP's Second Wave: Maximizing the Value of Enterprise application. Retrieved August 27, 2009 from http://www.ctiforum.com/technology/CRM/w p01/download/erp2w.pdf

Ehie, I. C., \& Madsen, M. (2005). Identifying critical issues in enterprise resource planning (ERP) implementation. Computer in industry, 56.

Esteves, J. M., \& Pastor, J. A. (1999). An ERP Lifecycle-based Research Agenda. First International workshop in Enterprise Management and Resource Planning: Methods, Tools and Architectures.

Esteves, J., \& Pastor, J. (2001). Analysis of Critical Success Factors Relevance Along SAP Implementation Phases. Americas Conference on Information Systems (AMCIS). AISeL.

Govindaraju, R. (2002). Effective Enterprise Systems Implementations. Dissertation, University of Twente, Enschede, The Netherland.

Govindaraju, R., Fisscher, O., \& de Bruijn, E. J. (2001). A Framework for Studying Enterprise Systems Implementations from an Organizational Perspective. Jurnal Teknik dan Manajemen Industri , 21 (1).

Gupta, M., \& Kohli, A. (2006). Enterprise resource planning systems and its implications for operations function. Technovation , 26.

Handayani, F. (2009). Pengembangan Model Kausal dan Evaluasi Kesuksesan Sistem Enterprise Resource Planning (ERP) di PT. Danone Dairy Indonesia. Skripsi, Institut Teknologi Bandung, Bandung.

Jones, M. C., Cline, M., \& Ryan, S. (2004). Exploring knowledge sharing in ERP implementation: an organizational culture framework. Decision Support Systems , 41.

Kræmmergaard, P., \& Møller, C. (2000). A Research Framework for Studying the Implementation of Enterprise Resource Planning (ERP) systems. Proceedings of IRIS 23. Uddevalla. 
Kumar, V., Maheshwari, B., \& Kumar, U. (2002). ERP Systems Institutionalization: A Model For Organizational Effectiveness. ASAC 2002 Conference. Winnipeg, Manitoba.

Markus, M. L., \& Tanis, C. (1999). The Enterprise System Experience - From Adoption to Success. Retrieved 2009 йил 29-August from http://pro.unibz.it/staff/ascime/documents/ER P\%20paper.pdf

Martua, T. (2006). Identifikasi Pengaruh Karakteristik Relative Advantage, Compatibility, dan Complexity Terhadap Behavior Change dalam Ruang Lingkup Implementasi Sistem Enteprise Resource Planning (ERP) (Studi Kasus: PT. Mitsubishi Chemical Indonesia). Tesis, Institut Teknologi Bandung, Bandung.

Motwani, J., Mirchandani, D., Madan, M., \& Gunasekaran, A. (2002). Successful implementation of ERP projects: Eviden from two case studies. International Journal of Production Economics.

Muharni, Y. (2008). Pengembangan Framework PostProject ERP (Studi Kasus pada Dua Perusahaan Besar di Indonesia). Thesis, Institut Teknologi Bandung, Bandung, Indonesia.

Nah, F. F.-H., Lau, J. L.-S., \& Kuang, J. (2001). Critical factors for successful implementation of enterprise systems. Business Process Management Journal, 7 (3).

Nicolau, A. (2004). ERP Systems Implementation: Drivers of Post-Implementation Success. Decision Support in an Uncertain and Complex World: The IFIP TC8/WG8.3 International Conference. Prato-Italy.

Nisfiannoor, M. (2008). Pendekatan Statistika Modern untuk Ilmu Sosial. Jakarta: Penerbit Salemba Humanika.

Novriani, M. (2008). Pengembangan Model dan Evaluasi Kesuksesan ERP pada Fase Post Implementasi Di PT. Indosat Tbk. Skripsi, Institut Teknologi Bandung, Bandung.
Nugroho, B. A. (2005). Strategi Jitu Memilih Metode Statistik dengan SPSS. Yogyakarta, Indonesia: CV. Andi Offset.

Rajagopal, P. (2002). An innovation-diffusion view of implementation of enterprise resource planning (ERP) systems and development of a research model. Information \& Management, 40.

Ross, J. W., \& Vitale, M. R. (2000). The ERP Revolution: Surviving vs. Thriving. Information Systems Frontiers, 2 (2).

Sekaran, U. (2006). Metodologi Penelitian untuk Bisnis, Buku 2 (Edisi 4 ed.). Jakarta, Indonesia: Salemba 4.

Shang, S., \& Seddon, P. B. (2000). A Comprehensive Framework for Classifying the Benefits of ERP Systems. Americas Conference on Information Systems (AMCIS). Association for Information Systems.

Shanks, G., Parr, A., Hu, B., Corbitt, B., Thanasankit, T., \& Seddon, P. (2000). Differences in Critical Success Factors in ERP Systems Implementation in Australia and China: A Cultural Analysis. 8th European Conference on Information Systems ECIS. Vienna-Austria.

Stefanou, C. J. (2000). The Selection Process of Enterprise Resource Planning (ERP) Systems. Americas Conference on Information Systems (AMCIS) AMCIS 2000 Proceedings. Association for Information Systems.

Teo, T. S., \& Ang, J. S. (1999). Critical success factors in the alignment of IS plans with business plans. International Journal of Information Management , 19, 173-185.

Umble, E. J., Haft, R. R., \& Umble, M. M. (146). Enterprises resource planning: Implementation procedures and critical success factors. European Journal of Operation Research .

Van Grembergen, W., \& De Haes, S. (2008). Implementing Information Technology Governance: Models, Practices, and Cases. New Your: IGI Publishing. 